\title{
Learning to solve ICT/informatics-based problems
}

\author{
Mary Webb \\ Department of Education and Professional Studies, King's College London, Franklin-Wilkins \\ Building, London SE1 9NN, United Kingdom
}

mary.webb@kcl.ac.uk

Key words: Cognition, ICT, Informatics, Learning Models, Pedagogy

\begin{abstract}
The need for developing a pedagogy for ICT/informatics has been identified. While a great deal of research and thinking has focused on theories of learning in relation to ICT this has concentrated on using ICT rather than learning about ICT or Informatics. The links between theories of learning and practice of teaching are, therefore, much less clear for ICT. The nature of the ICT curriculum is examined in order to identify how particular theories of learning may inform the development of pedagogy for ICT. The components of a model of problem solving that fits in with the primary emphasis of ICT/Informatics courses are explored in relation to key learning theories. Important pedagogical implications are identified.
\end{abstract}

\section{INTRODUCTION}

Recent evidence of standards of teaching and learning of ICT in England still reveals significant shortcomings. These deficiencies, together with the perceived importance of developing ICT knowledge and skills, has led to calls for the elucidation of a pedagogy for ICT. In England the term ICT is used to describe both the study of computers and other technologies that are used for communications and Information Systems and the use of ICT tools and processes in other areas of the curriculum. This paper focuses on ICT as a subject.

The original version of this chapter was revised: The copyright line was incorrect. This has been corrected. The Erratum to this chapter is available at DOI: 10.1007/978-0-387-35663-1_34 
An examination of the pedagogical reasoning process as it applies to the teaching of ICT, revealed a number of problems for ICT teachers and led to the identification of actions to address these problems (Webb, in press). These include classroom-based research, informed by appropriate theories of learning, to identify pedagogical content knowledge and subject specific interpretations of general pedagogical knowledge.

In long-established subjects such as science the links between theories of learning and practice of teaching have developed over many years (Adey 2001). While a great deal of research and thinking has focused on theories of learning in relation to ICT this has concentrated on using ICT rather than learning ICT or Informatics. Therefore the links between theories of learning and practice of teaching are much less clear for ICT.

Before we can analyse in detail how specific theories of learning might inform the development of pedagogy for ICT, we need a clear idea of the nature of the ICT curriculum and the learning processes that are involved. In this paper I identify and discuss the nature of key concepts and processes of ICT and clarify the types of knowledge, skills and processes that students are expected to learn. This facilitates examination of how selected theories of learning may inform the development of an appropriate pedagogy. A first step is the clarification of the nature of the curriculum for learning ICT itself.

\section{THE ICT CURRICULUM}

In the UK, courses at GCSE level aimed primarily at 14-16 year-olds, develop knowledge, skills and processes associated with analysing, designing and implementing ICT-based systems. The following aims of the AQA GCSE ICT syllabus indicate the nature of the subject:

- "Choose, use and design information and communication systems to carry out a range of tasks and to solve problems, making effective use of appropriate principles and techniques."

- "Develop a broad and balanced experience of the range of information and communication systems and their applications and an understanding of their capabilities and limitations." (Assessment and Qualifications Alliance 2000)

These courses typically have a substantial coursework element (normally accounting for $60 \%$ of the assessment) that focuses on solving problems through the use of ICT. This emphasis on problem solving through the use of ICT is also central to informatics courses (Hubwieser and Friedrich 1997).

For the GCSE in ICT students are expected to document the analysis, design, implementation and evaluation of their systems. A brilliant implementation without evidence of other elements of the process is only 
eligible for a very small percentage of marks. The educational purpose is to generate understanding of the nature of development of ICT systems (the systems development life cycle) by ICT professionals and to learn the skills, processes and strategies involved for solving simple problems that model tasks the professionals perform. Hubwieser and Friedrich emphasise the importance of the teacher choosing suitable problems as close to the student's experience as possible and encouraging all students to learn and use appropriate concepts of representation and techniques for carrying out the stages of the systems development life cycle.

The requirements for courses for 11-13 year-olds are less clearly specified (Webb, in press) but some schemes of work do recognise the need for understanding of the systems development life cycle and the development of the above-mentioned concepts and techniques (ACITT 1998; QCA 2000). The ACITT scheme introduces the systems life cycle in the first module of their course at age 11. The QCA scheme is less clear about the need to underpin the curriculum with the systems approach, only providing an overview of the systems life cycle in their final module normally tackled by 13 year-olds.

ICT courses in England then emphasise practical problem solving through the use of ICT and the development of the knowledge, skills and processes that are required for these activities. There remains a lack of clarity about how progression in understanding should develop for 11-13 year-olds.

\section{THE LEARNING PROCESS}

\subsection{Problem solving}

There is no generally accepted model of problem solving that characterises the process. The CRESST model defines the main components of problem solving and incorporates many issues identified in a review of problem solving, predominantly from cognitive science research (O'Neil 1999).

The definition of problem solving used for this model is:

"Problem solving is cognitive processing directed at achieving a goal when no solution method is obvious to the problem solver." (Mayer and Wittrock 1996) 
This definition can be applied to a wide range of problems but to make it really useful it is necessary to interpret each component specifically in relation to ICT-based problem solving.

An advantage of the model, shown in Figure 1, is that it reveals the wide range of understanding and skills required to solve problems and hence points to the complexity of teaching ICT where a predominant focus is on solving real problems. By the time students tackle GCSE coursework they need to be competent in all aspects of the model as they apply to ICT-based problems.

\subsection{Content understanding}

Content understanding is an integral component of the CRESST model of problem solving. Numerous studies that compared people who are competent in solving problems in various domains with beginners who are less proficient, found that competent problem-solvers are able to apply relevant principles from their content knowledge to the analysis and solution of problems.

What content understanding is needed for ICT? When and how should it be developed? Content understanding as specified by Hubwieser and Friedrich and GCSE syllabuses (Assessment and Qualifications Alliance, 2000) can be classified into:

- concepts and techniques of representation of data, knowledge and processes;

- metaphors and capabilities of types of application software;

- structure and functions of ICT systems;

- $\quad$ social, legal and ethical issues.

I believe there are differences in the approaches that are appropriate for teaching and learning of these four types of content understanding. The first two types are particularly critical in the problem-solving activities in which students engage for their coursework. Both types of content understanding incorporate declarative and procedural knowledge. The latter can only be learned through practice in problem-solving situations according to the "ACT theory of learning and problem solving" (Anderson et al 1995). According to this theory, declarative knowledge (e.g. that dataflow diagrams consisting of flows, inputs, outputs and stores can be used to model the logical flow of data around a system) is relatively easily taught and learnt probably by instructionist methods. The procedural knowledge that enables students to construct dataflow diagrams from descriptions of systems can only be learnt through practice. This will be obvious to ICT teachers for whom a typical teaching sequence on this topic might be: 
1. The teacher explains concepts of dataflow diagrams and models an everyday example as well as a standard data-processing example.

2. The students construct simple dataflow diagrams of everyday examples.

3. The students draw dataflow diagrams for modelling parts of their designs for their coursework.

Metaphors and capabilities of types of application software also include both declarative and procedural knowledge. However, for developing understanding of this content, as well as emphasizing the importance of practice, I suggest benefits may be gained by adopting minimalism (Carroll 1998).

Minimalism is described as an action and task-based approach to instruction that emphasises the importance of realistic activities and experiences and focuses on errors for effective learning. Whilst it is not always possible to perform real tasks as they may be too complex, minimalist design of teaching and learning tasks would include elements of real tasks and provide scaffolding to enable learners to achieve them. The nature of the tasks would contribute to learners' motivation. An emphasis on getting learners started quickly on practical activities does not mean theoretical concepts are ignored - rather they are developed at appropriate points during a practical task. This approach appears to match what many ICT teachers strive to achieve, although the latter may not have defined their design principles or framework.

Carroll describes the minimalist movement as more a matter of zeitgeist and refinement than of radical innovation. The minimalist approach derives predominantly from writing software guides for adults but its use has extended into many other areas. It is underpinned by learning theory including Piaget's theory of learners as active constructors of their knowledge and Bruner's concept of scaffolding. Although minimalism suggests an approach that is simple and straightforward, it must be stressed that while the aim is to make the learning process simple and achievable, considerable effort and expertise is required to design learning situations that adhere to minimalist principles.

Much needs to be done in adapting minimalism to ICT teaching. However the principles, while grounded in popular learning theory, provide a more practical and focused basis for developing pedagogy than the general calls for a constructivist approach to teaching ICT. Little research or development has looked at the relationship between paper-based support materials, electronic support materials and teacher support. This issue should be addressed when establishing pedagogy for ICT. 


\subsection{Problem solving strategies}

Domain-specific problem solving strategies may develop through the teaching of content understanding of representational techniques as long as the teaching and learning situation provides practice in their use. The use of a representational technique, such as a systems flowchart to model a problem solution, is a domain-specific problem solving strategy.

Domain independent strategies - the use of analogy or identification of boundaries of problems - can only be understood through tackling problems and focusing on the strategies used. There is a key role for the teacher in modelling strategies and scaffolding students while they are developing strategies.

The process of transfer of problem solving strategies is not always successful. Mayer and Wittrock argue that students may fail to recognise similarities between known and unknown problems unless there are explicit explanations and examples of similarly worked out problems. They consider it important that the students are initially able to convert the "problem-aspresented" into "an internal representation of the problem". Their research indicates that the student must develop cognitive and metacognitive strategies to accomplish this transfer of understanding.

\section{SELF-REGULATION}

Boekaerts (1997) summarises evidence from a range of studies that show that students who have more metacognitive knowledge in relation to a subject-matter domain, demonstrate superior strategy use and are better problem solvers. She concludes that self-regulation can be taught but that pedagogical strategies, including modelling, scaffolding and coaching need further research. With regard to metacognition I suggest ICT teachers should build on successful approaches in other subject areas. In particular the approach of Cognitive Acceleration in Science Education (CASE) might be adapted to ICT education (Adey 1999).

CASE activities are founded in theories of cognitive development described by Piaget and by Vygotsky. They are based on the idea that the solution of problems, with carefully graded help (mostly through questioning) from a teacher or more able peer, leads not only to a solution of that problem but also to the general stimulation of the pupils' cognitive processing mechanism. A carefully structured series of such experiences will have a permanent and irreversible effect on the subject's cognitive development. This is borne out by significant improvements in achievement 
of CASE pupils compared with control groups not just in Science (where CASE-intervention took place) but also in English and Mathematics.

CASE activities are tightly-focussed problem-solving tasks designed to develop understanding of scientific concepts related to Piagetian formal operations that students find difficult to grasp. In order to design similar activities for ICT it will be necessary to identify specific cognitive processes that students find difficult in ICT-based problems. Some processes may be drawn from those identified by the CASE project such as the understanding and use of variables, values and relationships.

CASE activities emphasise the importance of reflection, and in particular of social exchange, in the development of thinking as well as the development of knowledge. Pupils are encouraged to talk with the teacher or each other about how they are tackling and solving the problem or what difficulties they are finding. They become more conscious of their own thinking processes. This promotes cognitive development.

Two other important ideas used in the CASE materials are concrete preparation and bridging. Concrete preparation is the first phase of the activity when key words are introduced and practised and the context of the problem situation is made familiar through demonstration and questioning. The final phase of the activity is called bridging. In this process links are built between the type of reasoning being developed during the thinking activity and the use of that reasoning in other contexts. This bridging enables transfer to occur.

\section{CONCLUSIONS}

Problem solving is a large and essential component of the ICT curriculum in schools. The CRESST model of problem solving reveals the range of content understanding, skills and techniques that students need to learn to become effective problem solvers. I have argued that two key elements of content understanding required for ICT-based problem solving are concepts and techniques of representation of data, knowledge and processes and metaphors and capabilities of types of application software.

These may be best addressed by pedagogies based on Anderson's theory and on Carroll's minimalism respectively. The development of problem solving strategies depends on practice and appropriate scaffolding as well as techniques to develop cognition. A potentially fruitful approach is to develop a methodology based on that of CASE that would involve identifying key cognitive skills that students find difficult when solving problems in ICT and devising focused tasks. 


\section{REFERENCES}

ACITT (1998) Informatics Key Stage 3. ACITT, London.

Adey, P. S. (1999) Thinking science as a gateway to general thinking ability. In Teaching and learning thinking skills. J. H. M. Hamers, J. E. H. Van Luit and B. Csapo (eds.), Swets \& Zeitlinger, Netherlands, pp. 63-80.

Adey, P. (2001) 160 years of science education: an uncertain link between theory and practice. School Science Review, March 2001, 82. pp41-48.

Anderson, J. R., Corbett, A. T., Koedinger, K., and Pelletier, R. (1995) Cognitive tutors: Lessons learned. The Journal of Learning Sciences, 4, pp.167-207.

[http://act.psy.cmu.edu/ACT/papers/Lessons_Learned-abs.html]

Assessment and Qualifications Alliance (2000) General Certificate of Secondary Education ICT. AQA Guildford.

Boekaerts, M. (1997) Self-regulated learning: a new concept embraced by researchers, policy makers, educators, teachers and students. Learning and Instruction, Vol 7. No 2. Pp. 161186.

Carroll, J. M., (ed.) (1998) Minimalism Beyond the Nurnberg Funnel. MIT Press, Cambridge, Mass.

Hubwieser, P. and Friedrich, S. (1997) Teaching informatics as a subject. In Capacity Building for IT in Education in Developing Countries, London, G. Marshall and M. Ruohohen (eds.), IFIP Working Conference, Harare, Zimbabwe. Chapman \& Hall, London.

Mayer, R.E. and Wittrock, M.C. (1996) Problem-Solving Transfer. In Handbook of Educational Psychology, D. C. Berliner and R. C. Calfee (eds.), Simon \& Schuster Macmillan, New York. pp. 47-62.

O'Neil, Jr, H.F. ( 1999) Perspectives on computer-based performance assessment of problem solvlng. Computers in Human Behaviour, 15, pp. 255-268.

QCA (2000) Information and communication technology: A scheme of work for Key stage 3. Qualifications and Curriculum Authority, London.

Webb, M. E. (in press) Pedagogical reasoning: issues and solutions for the teaching and learning of ICT in secondary schools. 